
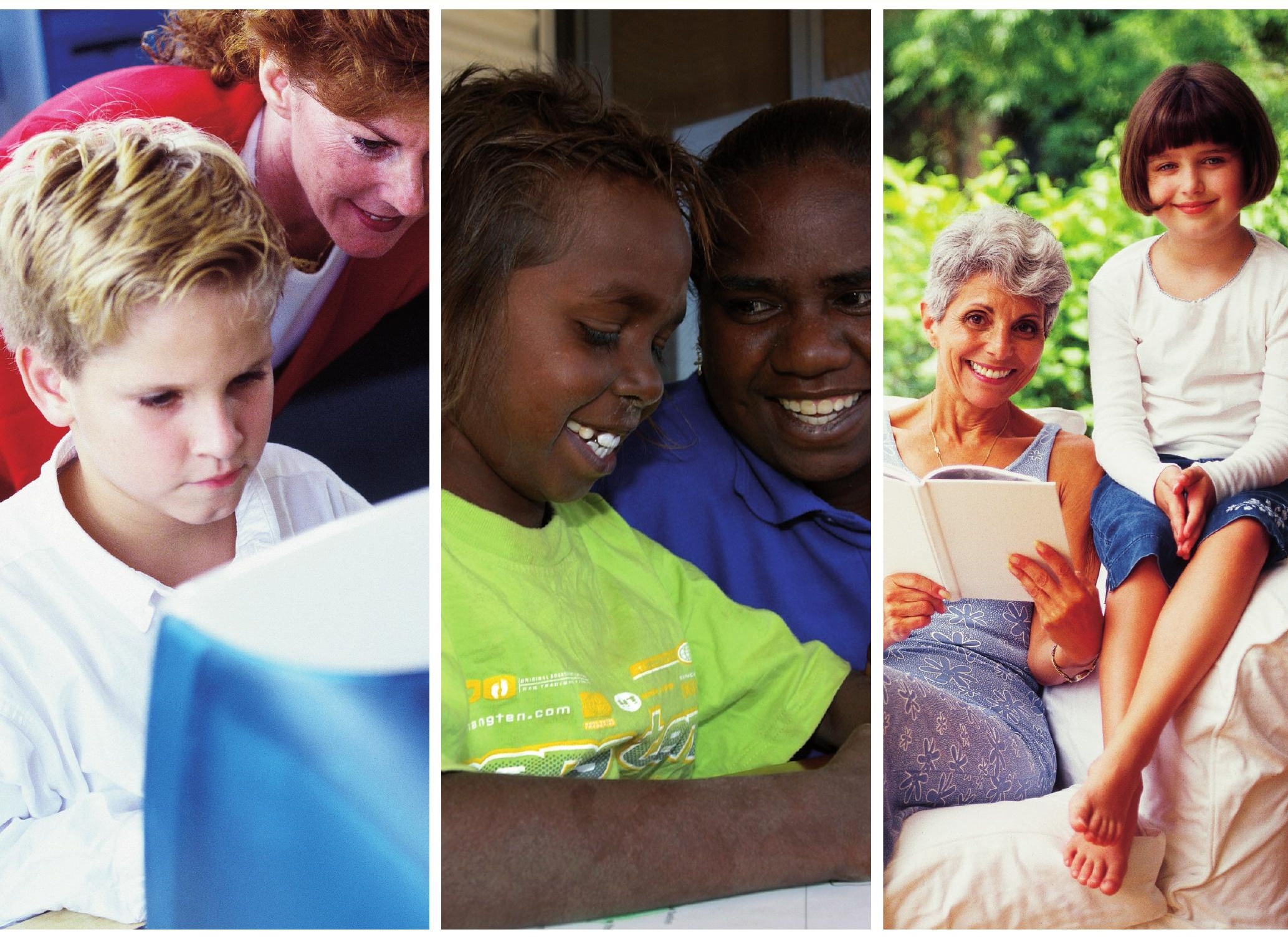

FAMILY - SCHOOL PARTNERSHIPS FRAMEWORK

A guide for schools and families 


\section{Q Contents}

1. Introduction 2

2. Vision 4

3. Principles which underpin effective Family-School Partnerships 4

4. Supporting Structures 4

5. Key Dimensions of Family-School Partnerships 5

6. Suggested Strategies for School Communities in 8 Developing Partnerships

7. Suggested Strategies for School Systems in Developing Partnerships 14

8. Glossary 15

9. Appendices 16

10. The Elements of Best Practice 19

11. Case Studies 20 


\section{Introduction}

\section{What are family-school partnerships?}

Family-school partnerships are collaborative relationships and activities involving school staff, parents and other family members of students at a school. Effective partnerships are based on mutual trust and respect, and shared responsibility for the education of the children and young people at the school.

Why are family-school partnerships important?

Families are the first educators of their children and they continue to influence their children's learning and development during the school years and long afterwards. Schools have an important responsibility in helping to nurture and teach future generations and families trust schools to provide educational foundations for their children's future. At the same time, schools need to recognise the primary role of the family in education. This is why it is important for families and schools to work together in partnership.

Research demonstrates that effective schools have high levels of parental and community involvement. This involvement is strongly related to improved student learning, attendance and behaviour. Family involvement can have a major impact on student learning, regardless of the social or cultural background of the family.

Family involvement in schools is therefore central to high quality education and is part of the core business of schools.

The aim of the Family-School Partnerships Framework is to encourage sustainable and effective partnerships between all members of the school community, including teachers, families, and students. These partnerships should:

- view each partner as making equally valuable contributions, while respecting different contributions;

- respect student needs and preferences;

- address barriers to involvement in schools by families, in particular Indigenous families, and actively help previously uninvolved families to become involved;

- create better programs, opportunities and learning for students;

- give families appropriate opportunities to contribute to school decision-making and governance; and

- contribute to professional satisfaction for principals and teachers.

Developing family-school partnerships may not always be easy. It requires commitment and time. Because of pressures and circumstances, many families will need special arrangements, or extra support, to enable them to become actively involved in their children's school lives, and to help their children get the most from school.

The results of this effort will be significant. Families that understand the education system and the difficulties schools face are a valuable source of support which schools cannot afford to underestimate. Schools that engage families in their children's learning are tapping in to a rich source of information and expertise and can help build communities. 
How is this different from what every school does already?

Schools vary considerably in their commitment to family-school partnerships and the energy and skills they apply to them.

Moving towards partnerships requires a significant change in attitudes by some schools and families in order to create relationships where they see one another as allies in education.

\section{What does the Framework contain?}

The Framework contains:

- a vision for improved partnerships between Australian families and schools;

- a set of principles to guide families and schools in developing partnerships;

- seven key dimensions of effective family-school partnerships;

- a set of strategies providing practical guidance to school communities and school systems in implementing and fostering family-school partnerships.

The Framework is based on existing good practice and provides an agreed national approach to guide schools and families working on these issues.

The Framework recognises that many positive developments and innovations are already occurring in schools and that a one size fits all approach to partnerships is not feasible. Partnerships need to be underpinned by broad principles and strategies but remain specific to school context, including family/community characteristics, school size, levels of schooling and student needs.

Why have a Framework?

The Framework is a resource for school communities. Its purpose is to encourage and guide schools, school systems, parent groups and families to support family-school partnerships.

Who is it for?

The Framework is intended for school systems, schools, school leaders (both staff and parents), families and other interested people working together to develop partnerships. The Framework is an opportunity to take stock and ask:

- to what extent are partnerships occurring?;

- in whose opinion are partnerships occurring?; and

- is there evidence from staff and parents on the performance of partnerships?

Who prepared it?

The Framework has been prepared by the national parent bodies in Australia - the Australian Council of State School Organisations (ACSSO), the Australian Parents Council (APC) - the Australian Government, and other key stakeholders, including State and Territory government and non-government school authorities, and school principals' associations. 
Families and schools work together as partners in the education of children and young people.

\section{Principles which underpin effective Family-School Partnerships}

1. All families and schools want the best for their children.

2. All children have the right to the opportunity to reach their full potential.

3. Families are the first and continuing educators of their children.

4. Effective schools provide a nurturing and supportive learning environment.

5. Families and schools value quality teaching and respect teachers' professional expertise.

6. Families and schools value the diversity of families and use this as a resource for building partnerships and communities.

7. Family-school partnerships are based on mutual responsibility, respect and trust.

8. Leadership is critical to building, maintaining and renewing partnerships.

9. Family-school partnerships improve student motivation and learning.

10. Family-school partnerships strengthen the connections between schools and their communities.

11. Partnerships can involve all organisations that support families and schools.

\section{Q Supporting Structures}

In order to create the conditions that enable effective family-school partnerships to be developed and sustained, the following supporting structures need to be in place at both systemic and school levels:

I. family-school action teams to plan, organise, implement and evaluate partnerships;

II. school policies and procedures which explicitly state and clearly integrate the principles and practices of effective partnerships;

III. support networks, to enable school communities to share ideas, issues and best practice; and

IV. accountability to the community, to report on successes and drive improvement in partnerships.

School communities are encouraged to review their current supporting structures, policies and procedures and develop new ones where necessary. This may include establishing a dedicated family-school action team of school leaders, teachers and parents (appointed by the parent body) - or using an existing working group that includes parents - to develop and coordinate partnership plans and activities.

Any successful partnership will involve parents, carers and families in preparation, planning, implementation and review. A dedicated family-school action team of teachers, school leaders and parents to develop and coordinate partnership plans and activities can provide the basis for improving partnerships more broadly. 
This family-school action team would:

- audit existing arrangements and practices and collect information on the views, experiences and wishes of teachers, parents, school leaders and students;

- confirm that the school leaders and the parent network endorse the concept of partnership and inform the school community;

- develop plans for implementation, setting goals, timelines and success indicators against the Key Dimensions of the Family-School Partnerships Framework;

- arrange training for action team members;

- implement agreed activities;

- evaluate the effectiveness of the partnership activities;

- continue to improve and coordinate practices against the Key Dimensions of the Family-School Partnerships Framework; and

- explore options for new partnerships.

\section{Key Dimensions of Family-School Partnerships}

The Family-School Partnerships Framework identifies seven dimensions as guidelines for planning partnership activities. These seven dimensions are:

A. communicating;

B. connecting learning at home and at school;

C. building community and identity;

D. recognising the role of the family;

E. consultative decision-making;

F. collaborating beyond the school; and

G. participating.

A brief description of each dimension is provided below.

\section{A. Communicating}

This key dimension emphasises that effective communication:

- is active, personal, frequent and culturally appropriate;

- is where schools go out of their way to make families feel welcome and valued;

- is a two-way exchange between families and schools;

- involves not only an exchange of information, but also an opportunity for schools and families to learn about each other;

- makes clear that families are genuine partners and can help solve big problems;

- builds bridges across cultural and language divides including actively seeking access to these families;

- needs to take into account cultural and linguistic diversity and not assume that all families communicate in the same way;

- is open to families' needs and attitudes;

- acknowledges and celebrates the families' input;

- is multi-dimensional - it may:

- be formal or informal,

- happen in different places (both in the school and in other sites such as community centres), and

- use different methods (oral, written, face-to-face, phone, email, etc). 
Family-school communication needs to be taken seriously and must be valued, recognised, and rewarded by schools and education systems. It is essential to provide teachers and school leaders with education and training programs to prepare them to communicate effectively with families in an approachable manner. It is equally important to empower and encourage families to communicate effectively with schools.

\section{B. Connecting Learning at Home and at School}

This key dimension emphasises:

- understanding by families and schools of the overlap between the home and school environments;

- the connection between successful partnerships and the child's learning, including the importance of high expectations from both teachers and parents to the child's success at school;

- families and schools working together to create positive attitudes to learning in each child;

- ensuring families are informed about and understand their child's progress;

- families and schools valuing and using the skills and knowledge children bring both from the home to the school and from the school to the home;

- families and schools recognising and using learning opportunities in the home environment;

- parents working with teachers in the educational decision-making process for their individual child; and

- schools becoming a venue and agent for parental self-growth, learning and the development of new skills.

\section{Building Community and Identity}

This key dimension emphasises activities that improve the quality of life in a community while honouring the culture, traditions, values and relationships in that community. By including activities that shape students' sense of identity and culture, schools can build a sense of community in each student. The work of schools includes aspects of the social, emotional, moral and spiritual development of young people. Thus schools have a role to play in promoting both personal growth and cultural renewal. Schools can act as a focal point for communities to come together and engage in capacity-building.

\section{Recognising the Role of the Family}

This key dimension emphasises that as primary educators of their children, parents and families have a lasting influence on their children's attitudes and achievements at school. They can encourage their children's learning in and out of school and are also in a position to support school goals, directions and ethos. Parents look to schools to provide secure and caring environments for their children. 
Families and schools can reach mutual understanding of each other's roles and priorities in partnerships by:

- exploring the nature of parent and family's role in the education of children to develop mutual understanding;

- offering strategies for family support and encouragement of children's learning at school;

- organising workshops/discussions/meetings and demonstrations around areas such as literacy and numeracy, home and classroom work, raising resilience and confidence in young people, transitions and careers and so on, depending on local needs and priorities;

- ensuring families understand school goals, curriculum and the social objectives of schooling;

- ensuring schools understand family, parent and community priorities;

- ensuring schools are sensitive to parents' sensibilities;

- ensuring schools are realistic, patient and brave;

- establishing an environment where schools show leadership which is visible and available;

- helping schools become a place that parents can call their own including creating real roles for parents who come into the school;

- building relationships; and

- developing skills, such as communication, collaboration and conflict management.

\section{E. Consultative Decision-Making}

This key dimension emphasises that parents are entitled to be consulted and participate in decisions concerning their own children.

Parents can play meaningful roles in the school decision-making processes. Training and information to make the most of those opportunities can be provided as part of the partnership activities.

An inclusive approach to school decision-making and parental involvement creates a sense of shared responsibility among parents, community members, teachers and school leaders. In turn, shared responsibility:

- ensures that parents' values and interests are heard and respected;

- makes the school more accountable to its community;

- ensures that the values and opinions of families are sought outside the formal school structures; and

- ensures that contact with Indigenous parents from within the community is sought to ensure their engagement in school decision making. 


\section{F. Collaborating Beyond The School}

This key dimension emphasises identifying, locating and integrating community resources. The wider community provides services which can strengthen and support schools, students and their families. Schools, families and students can assist the community in return. Schools are increasingly collaborating with partners such as:

- local businesses;

- after-school care providers;

- higher education;

- foundations; and

- other community-based agencies.

\section{G Participating}

This key dimension emphasises that families' time, energy and expertise can support learning and school programs in many ways. This may involve family members:

- working with students on learning activities in classrooms;

- participating in other school activities outside the classroom; or

- participating in activities outside the school itself; and

- supporting and valuing teachers.

Families participate in the school in a wide variety of ways and all contributions are valuable. Participation may involve families having the opportunity to do something that interests them and including activities that are not directly education-related.

\section{Suggested Strategies for School Communities in Developing Partnerships}

Outlined below are suggested strategies to develop partnerships based on each of the key dimensions. They are designed to support school communities in developing family-school partnerships, to assist them to reflect on their existing practices and plan for improvement. These strategies provide practical guidance for schools about how to initiate partnerships, how to help families to initiate partnerships, and how to have families' perspectives on issues represented in partnerships overall.

The different strategies are designed to build on each other with none of them being a 'cure-all' by itself. They are not intended to be exhaustive but are examples of good practice to help school communities build partnerships. Strategies can be added or modified for each key dimension and will also overlap across key dimensions.

Skills-building for families, school leaders and teachers is a crucial strategy for each key dimension. 


$\begin{aligned} & \text { 4, 5, 6, 7, A. Communicating } \\ & 810\end{aligned}$
A Family-School Action Team or Working Group can plan for
for example:
- conduct a survey to assess communication needs;
- review the newsletter for relevance, ease of language and
scope to provide feedback;
- consider the placement of 'welcome' signs around the
school;
- review current school practice on inviting parent and family
participation and consider how this can be improved;

- consider working with parents and families to develop a parent handbook of information on school rules, policies, mission and goals, curriculum standards and assessment procedures. Hold a launch event and publish it on the website or provide it to new parents;

- find out parent and family time availability for participation in schools events, workshops, etc.

- examine good 'front desk' reception practice, including bilingual office staff where appropriate and training in cultural sensitivity and dealing with difficult people;

- set in place alternative methods of parent-teacher interviews when personal circumstances prevent parents from attending a face-to-face meeting, including options for telephone and email contact;

- consider the appointment of a school contact person/s, such as a parent-school liaison officer or an Indigenous homeschool liaison officer, to assist and support parents in their interactions with the school (i.e. home/school liaisons);

- consider education and training programs for teachers and school leaders that prepare them to communicate with parents effectively and extend their reporting skills, including training in Indigenous history and culture and in having the ability to ensure cultural inclusiveness in their teaching practice;

- investigate programs to welcome new families, including induction kits developed by parents that are in user-friendly language and font size;

- arrange for folders of student work to be sent home regularly for review and comment;

- establish agreed strategies for dealing with incidents at school;

- appoint class-parent representatives, who can become a welcoming informal network of support;

- involve students, especially older students, in interviews and other communications from the school. 


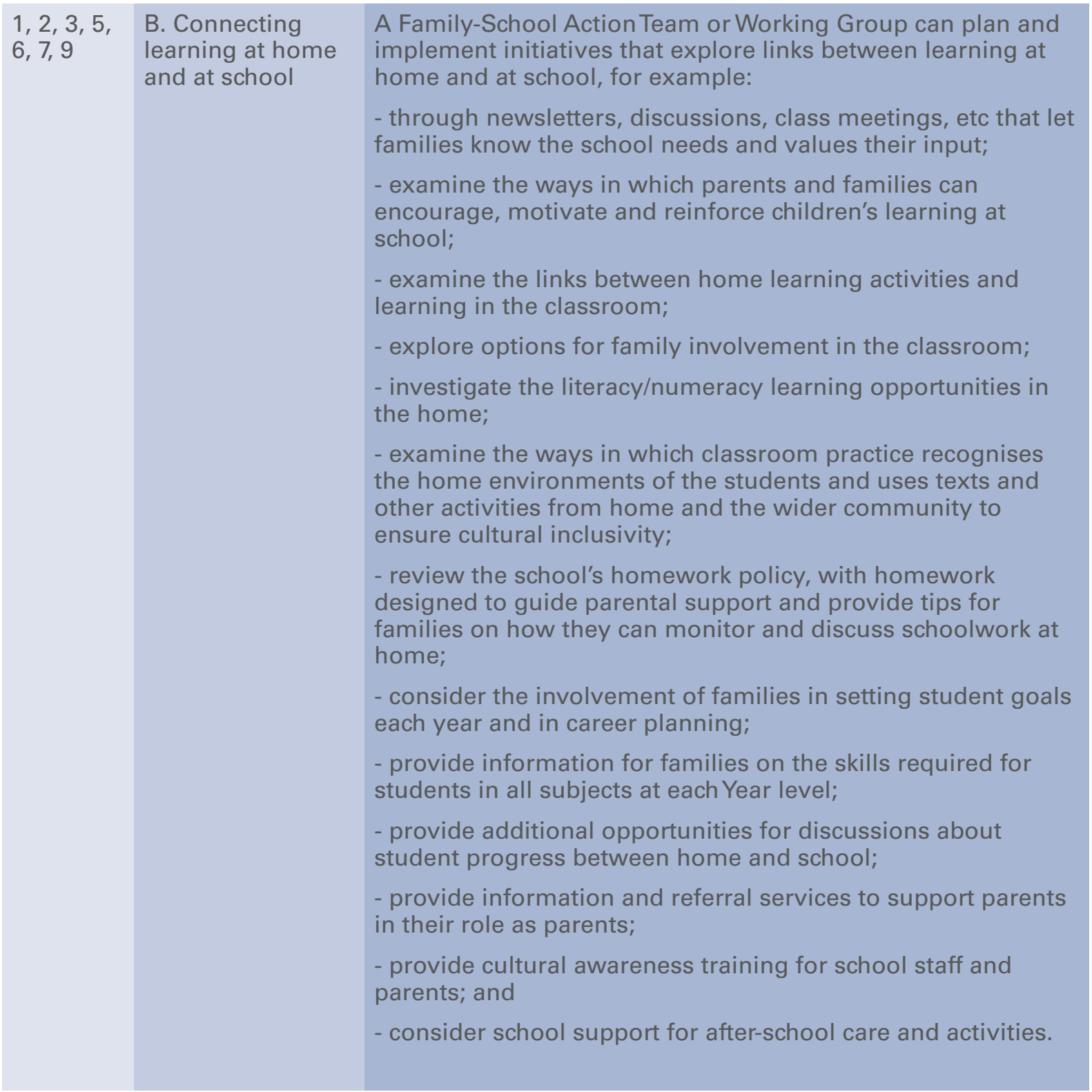




\begin{tabular}{|c|c|c|}
\hline $\begin{array}{l}2,4,6,10, \\
11\end{array}$ & $\begin{array}{l}\text { C. Building } \\
\text { community and }\end{array}$ & $\begin{array}{l}\text { A Family-School Action Team or Working Group can plan to } \\
\text { build a sense of community through the school - for example: }\end{array}$ \\
\hline & & $\begin{array}{l}\text { - consider and implement ways in which the school can } \\
\text { become a community resource, eg for adult learning and } \\
\text { community meetings; }\end{array}$ \\
\hline & & $\begin{array}{l}\text { - provide a place for potential parents and students of the } \\
\text { school to meet and participate in programs, eg for early } \\
\text { literacy learning, health care, etc.; }\end{array}$ \\
\hline & & $\begin{array}{l}\text { - assist the resettlement of new migrants, through the work of } \\
\text { English as a Second Language teachers and families; }\end{array}$ \\
\hline & & $\begin{array}{l}\text { - invite people in the broader community to attend school } \\
\text { functions; }\end{array}$ \\
\hline & & $\begin{array}{l}\text { - invite local civic and service groups to become involved in } \\
\text { the school in a variety of ways, such as mentoring students } \\
\text { and speaking to classes; }\end{array}$ \\
\hline & & $\begin{array}{l}\text { - collaboratively develop community driven programs that } \\
\text { assist to revive and maintain Indigenous languages and } \\
\text { cultures; }\end{array}$ \\
\hline & & $\begin{array}{l}\text { - create connections with local health and welfare services } \\
\text { to facilitate access to such support for the school community } \\
\text { members; }\end{array}$ \\
\hline & & $\begin{array}{l}\text { - develop participative and inclusive approaches to the design } \\
\text { of values linked education across curriculum. }\end{array}$ \\
\hline $\begin{array}{l}3,4,5 \\
7,8\end{array}$ & $\begin{array}{l}\text { D. Recognising } \\
\text { the role of the }\end{array}$ & $\begin{array}{l}\text { A Family-School Action Team or Working Group can work to } \\
\text { build greater recognition of the role of the family, for example: }\end{array}$ \\
\hline & & $\begin{array}{l}\text { - assess whether school arrangements meet good practice for } \\
\text { partnership between families and the school; }\end{array}$ \\
\hline & & $\begin{array}{l}\text { - survey parents, families and community members to } \\
\text { determine their needs and priorities; }\end{array}$ \\
\hline & & $\begin{array}{l}\text { - develop and distribute a written policy, in consultation with } \\
\text { the school community, on family-school partnerships; }\end{array}$ \\
\hline & & - conduct formal and informal forums which discuss: \\
\hline & & - $\quad$ parents' role as the first educators of their children; \\
\hline & & $\begin{array}{l}\text { the research which links parental support and } \\
\text { involvement at school with improved learning } \\
\text { outcomes for children and improved school ethos; }\end{array}$ \\
\hline & & $\begin{array}{l}\text { - identify parents/groups of parents to present the forums to } \\
\text { their parent peers; }\end{array}$ \\
\hline & & $\begin{array}{l}\text { - organise discussions, meetings or workshops around areas } \\
\text { of school goals, eg resilience, literacy and numeracy, which } \\
\text { allow parents to share their experience and understandings of } \\
\text { parenting, school goals and school ethos. }\end{array}$ \\
\hline
\end{tabular}




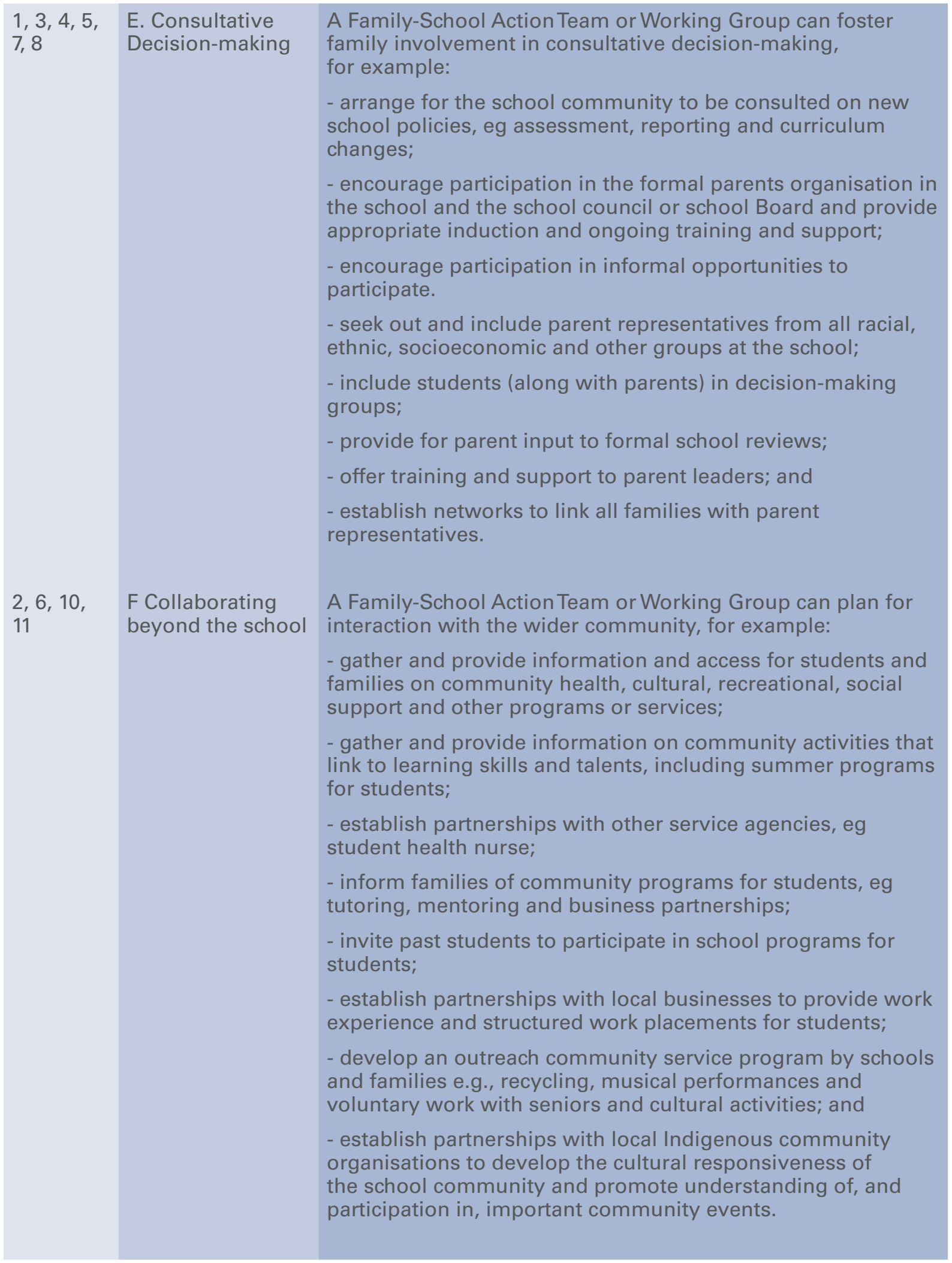




$\begin{array}{ll}\text { 1, 3,4,6, G. Participating } & \text { A Family-School Action Team or Working Group can plan the } \\ \text { support of volunteers and greater participation of families and } \\ \text { parents, for example: } \\ \text { - assess the volunteer needs of schools and list the many } \\ \text { ways parents and families can participate and interact with } \\ \text { school and the school community; } \\ \text { - develop a policy for recruitment, training, goal setting and } \\ \text { recognition for volunteers; } \\ \text { - ask family members how they would like to participate at } \\ \text { their child's school and respond in a timely manner to those } \\ \text { indications, i.e. establish a skills bank; } \\ \text { - invite family and community members to become involved } \\ \text { as guest teachers, guest speakers about their jobs/career } \\ \text { opportunities, excursion chaperones, tutors/mentors, sport } \\ \text { coaches, tuckshop helpers, and so on; } \\ \text { - implement flexible schedules for volunteers, assemblies and } \\ \text { events, so that all are able to participate; } \\ \text { - invite parents to volunteer to have students 'work shadow' } \\ \text { them; } \\ \text { - arrange working parties or committees for parent leadership } \\ \text { and participation, eg on safety or student behaviour; } \\ \text { - make sure parental involvement in children's learning is a } \\ \text { recognised topic of staff meetings, professional development } \\ \text { and in the induction of new staff. } \\ \end{array}$




\section{Q Suggested Strategies for School Systems in Developing Partnerships}

As a first step in developing excellent partnership programs, school systems (government, Catholic and Independent schools) are encouraged to identify a Partnerships Leadership Team to oversee and coordinate their work with families, and to connect with the parent body in their system. Following are examples of practices that system leadership teams, in partnership with the parent body, can use to encourage strong partnerships initiatives in schools:

- review or develop a policy on family-school partnerships;

- write an annual Action Plan for partnerships;

- provide resource materials to assist schools with partnership programs;

- establish a clearinghouse of information on best practices and research findings;

- conduct state-wide conferences to encourage the exchange of good practices and solutions to challenges in implementing partnership programs;

- work with universities to prepare new teachers to conduct effective partnerships;

- consider the ability to develop and maintain partnerships when considering the appointment of school leadership personnel;

- celebrate and recognise excellent partnerships in schools, eg through awards;

- identify a budget for partnership activities in schools;

- provide cross-school training for school Principals, teachers and families to increase their partnership skills;

- publicise family-school partnership activities in the mass media;

- work with business and industry to establish flexible leave policies so parents can attend activities at their children's schools;

- support and consult regularly with parent groups at the system level;

- explicitly seek and value the input of families; and

- maintain outreach and sustainability. 


\section{Q Glossary}

Families

Parents

Partnership

Principles

School community
In this paper, the term 'families' is used to describe any of the wide variety of home arrangements that people establish to care for and rear children.

"There is abundant evidence that Australian families are undergoing rapid change. The diversity of families is evident in the growth of non-traditional family structures. Family structure can be defined in terms of parents' relationships to children in the household (for example, biological or non-biological), parents' marital status and relationships history (for example, divorced, separated, remarried), the number of parents in the family, and parents' sexual orientation." (Wise, 2003)

In this paper, the term 'parents' includes all types of parental figures including carers.

The central characteristics of effective family-school partnerships include:

- sharing of power, responsibility and ownership, though with each party having different roles;

- a degree of mutuality, that begins with the process of listening to each other and that incorporates responsive dialogue and 'give and take' on both sides;

- shared aims and goals based on a common understanding of the educational needs of children; and

- commitment to joint action, in which parents, students and teachers work together. (Bastiani, 1993)

Partnerships are a collaborative relationship designed primarily to produce positive educational and social effects on the child while being mutually beneficial to all other parties involved. (Lueder, 1998)

A statement encapsulating a fundamental concept for action that guides effective practice. The principles in this document are recommended guidelines for developing and sustaining effective family-school partnerships.

The school community is generally considered to include students, families, school staff, other professionals, other support staff and volunteers. The school community may also include members of other organisations in the wider community who support the operation of the school. 


\section{Appendices}

\section{Acknowledgements}

The Australian Council of State School Organisations (ACSSO), the Australian Parents Council (APC) and the Australian Government wish to thank and acknowledge the following Family-School Partnerships Roundtable participants, who contributed to the development of this Framework:

Atkinson, Ms Geraldine, Chairperson, Victorian Aboriginal Education Association Incorporated, Victoria

Aulich, Hon Terry, Executive Officer, Australian Council of State School Organisations (ACSSO), Australian Capital Territory

Avenell, Mr Ken, President, Australian Council for Educational Leaders (ACEL), Queensland

Bain, Mr Chris, Principal Policy Officer, Strategic Policy and Education Futures Division Queensland Department of Education and the Arts, Queensland

Beach, Mr Jack, Federal President, Isolated Children's Parents' Association of Australia (ICPA), Queensland

Bloomfield, Ms Auriel, Executive Director, Change Management Team, Commonwealth Department of Education, Science and Training (DEST), Australian Capital Territory

Bosch, Ms Caz, Vice President, Federation of Parents and Friends Association of South Australian Catholic School, South Australia

Boucher, Ms Susan, Australian Principals Associations Professional Development Council (APAPDC), South Australia

Brierley, MrTed, Australian Secondary Principals Association (ASPA), Victoria

Brown, Mr Joe, Senior Policy Officer, Indigenous Education Division, Department of Employment, Education andTraining, Northern Territory

Bundy, Mrs Judith, President, Australian Council of State School Organisations (ACSSO), South Australia

Carroll, DrTom, Carroll Communications, New South Wales

Cashen, Ms Jacinta, President, Victorian Council of State School Organisations (VICSSO), Victoria

Clarke, Ms Helen, Manager, Stakeholder \& Community Liaison Unit, Department of Education and Training, Victoria

Clayton, Ms Kristy, Student, Hilliard Christian School, Independent Schools Council of Australia (ISCA), Tasmania

Cuttance, Professor Peter, Centre for Applied Education Research (CAER), University of Melbourne, Victoria

Dalton, Mr Ian, President, Tasmania Catholic Schools Parents and Friends Federation, Tasmania 
Daniels, Ms Rita, Executive Member, Association of Principals of Catholic Secondary Schools of Australia (APCSSA), Australian Capital Territory

Day, Mrs Hazel, Executive Officer, Association of Heads of Independent Schools of Australia (AHISA), Victoria

Draybi, Ms Debbie, Youth Deputy Chair, Federation of Ethnic Communities' Councils of Australia (FECCA), New South Wales

Duffie, Ms Jan, Principal Research Fellow, Australian Institute of Family Studies, (AIFS), Victoria

Dunne OAM, Mr Leo, President, Australian Parents Council (APC), Queensland

Flood, MrTerry, Teacher, MacKillop College, National Catholic Education Commission, Australian Capital Territory

Goos, Dr Merrilyn, Researcher, School of Education, University of Queensland, Queensland

Gouldson, Ms Sue, Manager, Officer of the Deputy Director-General, Department of Education andTraining, Western Australia

Hebblethwaite, Ms Judy, Director, Community Partnerships, Department of Education, Tasmania

Henry, Ms Pauline, Manager Indigenous Education Direct Assistance and Indigenous Education Strategic Initiatives Programs, Dubbo District Office, Commonwealth Department of Education, Science and Training (DEST), New South Wales

Kilvert, Dr Paul, Director, Learning Resources and Service, Department of Education and Children's Services, South Australia

Koppe, Ms Rosemarie, Centre for Innovative Education, Queensland University of Technology, Queensland

Lonergan AM, Mrs Jo, Executive Director, Australian Parents Council (APC), New South Wales

Macgregor, Mr Rupert, Project Manager, Australian Council of State School Organisations (ACSSO), Australian Capital Territory

Mackay, MrTony, Facilitator, Incorporated Association of Registered Teachers of Victoria, Victoria

Marsh, Ms Dominique, Parent Partner Liaison Officer, National Catholic Education Commission (NCEC), Australian Capital Territory

McConchie, Mr Rob, Project Consultant, Solved at McConchie Pty Ltd, Australian Capital Territory

Mclnnes, Mr Duncan, Executive Officer, Parent Council (NSW), New South Wales

Mercer, DrTrish, Branch Manager, Quality Schooling Branch, Commonwealth Department of Education, Science andTraining (DEST), Australian Capital Territory 
Milson, Ms Beverley, Resource Manager, Primary Education and Early Childhood, Department of Education and Training, New South Wales

Motley, Ms Ruth, Manager, Policy and Program Coordination, Department of Education and Children's Services, South Australia

Morrell, Ms Robin, Teacher, Alfred Deakin High School, Australian CapitalTerritory

Nicholas, Ms Emma, Student, Alfred Deakin High School, Australian CapitalTerritory

Norman, Mr Bev, Principal, Hilliard Christian School, Independent Schools Council of Australia (ISCA), Tasmania

Norton, Ms Grainne, Parent/Community Educator, National Catholic Education Commission (NCEC), New South Wales

O'Neill, Mr Mark, Vice-President (ACT), Australian Council of State School Organisations (ACSSO), Australian Capital Territory

Prout, Mr Ross, Assistant Manager, Community Partnerships and School Improvement, Department of Education and Training, Australian Capital Territory

Purdie, Dr Nola, Principal Research Fellow, Learning Processes and Contexts Research Program, Australian Council of Research (ACER), Victoria

Rhodes, Ms Anne, Executive Officer, Federation of Parents and Friends Association of South Australian Catholic School, South Australia

Roediger, Ms Wendy, Teacher, Nyindamurra School, Independent Schools Council of Australia (ISCA), Western Australia

Sheridan, Ms Lianne, Director, Learning and Improvement and Support Services, Department of Education and Training, New South Wales

Smith, Mr Les, Treasurer, Australian Council of State School Organisations (ACSSO), South Australia

Taylor, Ms Susan, Vice President (NT), Australian Council of State School Organisations (ACSSO), Northern Territory

Terry, Mrs Judy, Federal Vice-President, Isolated Children's Parents' Association of Australia (ICPA), Tasmania

Walsh, Ms Jan, Australian Primary Principals Association (APPA), Principal, Fadden Primary School, Australian Capital Territory

Ware, Mr Dennis, Acting Manager, Cairns District Office, Department of Education, Science and Training (DEST), Queensland

Zerna, Ms Jenice, Vice President (SA), Australian Council of State School Organisations (ACSSO), South Australia

\footnotetext{
* Please note - the Department of Education, Employment and Workplace Relations was formerly known as the Department of Education, Science and Training
} 


\section{THE ELEMENTS OF BEST PRACTICE}

1. Tap into the interests of parents.

2. Break down the teacher/non-teacher barrier by allowing for activities that are not directly education-related.

3. Use personal contact. It is the most effective form of communication.

4. Communicate, communicate, communicate.

5. Be a venue for, and agent of, parental self-growth.

6. Ask for, and value, the opinion of parents outside the formal school structures.

7. Create an environment that encourages parental autonomy.

8. Emphasise the connection with the child's education.

9. Go out of your way to make parents feel welcome and valued.

10. Build bridges across cultural and language divides.

11. Be sensitive to parents' sensibilities.

12. Be prepared to engage in community capacity-building.

13. Show leadership, be visible and available.

14. Be realistic, patient, and a bit brave.

15. Make it clear you think of parents as genuine partners.

16. Don't be frightened to ask parents to help solve big problems.

17. Open your mind to parents' needs and attitudes.

18. Appoint a parent/community liaison person to the staff.

19. Create a place that parents can call their own.

20. Acknowledge and celebrate parents' input. 


\section{Case Studies}

The following case studies are provided for your reference

\section{CASE A}

\section{Early Learning Centre and Parent and Community Centre}

The Early Learning Centre and the Parent and Community Centre are separate but related initiatives.

The Early Learning Centre prepares children aged from birth to four years for school, and at the same time educates their parents in how to assist with the child's development.

The Parent and Community Centre is a social support centre for parents and is open to anyone in the community. The Centre consists of a converted classroom, which the school has furnished in a homely manner with settees, easy chairs, dining table, and computer. A weekly meeting is held in the Centre, with free child care provided in an adjoining room. A small one-way window allows the parents to look in on their preschoolers while they are being cared for.

\section{Background}

This primary school of 280 students is located in a low socio-economic area where unemployment is high and family dysfunction common. About half the students are on the local equivalent of the Education Maintenance Allowance and there is a high percentage of single parents.

Six years ago, two senior teachers initiated the two elements of the project. At the time the school was looking for ways of arresting a long-term decline in enrolments and of staving off the possibility of being merged with another school or closed. The current Principal was new and almost one-third of the teaching staff had just been replaced. The school had become estranged from its community and a cultural change was under way to re-connect the school and community. The Early Learning Centre and Parent and Community Centre was welcomed by the Principal as a means to achieve the desired cultural change.

An experienced kindergarten teacher was enlisted to assist in setting up the Early Learning Centre. In addition, a parent who is highly active in school-related activities at a state and national level happened to work as a teacher's assistant at the school. She harnessed her energy to the cause and this clearly helped in maintaining momentum.

\section{Engaging Parents}

The teachers in the pre-Kinder program and in the early years of primary were sensitive to what parents were saying about wanting to bring their toddlers into the school, and creative in setting up a special program for them. They were also sensitive to what parents said about their social isolation, and proposed setting aside a room that could be used by parents as an informal meeting place.

The teachers obtained the support of the Principal, and at first provided leadership to the parents in setting up the community room. Gradually they relinquished this leadership role to the parents as the capacity to lead grew in some of the parents. 
The school recognised that many of its parents had had bad experiences of school, so took pains to ensure they could come and go without passing through the "front office", which is an intimidating place for some parents.

In summary, the school listened, responded to real needs, and created a welcoming place which was easy for apprehensive parents to enter.

\section{Researcher's observations}

The project appears to have acquired legitimacy among parents because it is responsive to their needs and because the school staff have allowed the parents to take control as their confidence and capabilities have grown.

Responsiveness to needs has been crucial, and the needs have been many. These parents needed somewhere to turn for advice about parenting and for "downloading" their emotional burdens among people who respected their confidences and did not judge them.

Friendships have been forged and networks created that have gone beyond the confines of the school community, breaking down isolation, building up selfconfidence, and allowing people to learn how to cope.

The benefits to the children's education appeared to be that the parents were more in touch with what was happening at school, felt integrated into the education of their children, felt empowered to communicate on an equal footing with teachers, and were fortified in being able to deal at home with the social circumstances that had a disruptive effect on the children.

Data on the effects of the community centre are largely anecdotal and qualitative. However, membership data indicate that the number of people coming to the community centre has grown from about six to about twenty, and they are beginning to include people from the wider community. Considering the history of disengagement between the parents and the school, and the significant level of disadvantage in the parent community, this is remarkable progress in a couple of years. It illustrates that these are long-term projects. 


\section{CASE B}

\section{Multicultural Learning Community}

This project was designed to build a stronger community between the school, with $90 \%$ of its students from non-English speaking backgrounds, and the parent community. Its aims were to:

- establish and maintain a play group for pre-school children and mothers of children who will be entering the school in Kindergarten;

- initiate a more comprehensive transition Program than in previous years, beginning in Term 3 with Kindergarten Orientation, and continuing in Term 42005 for children who would enter Kindergarten in 2006;

- conduct a series of eight bilingual workshops for parents with topics requested by parents, eg parenting skills, road-safety, anti-bullying, bilingualism; and

- conduct a parent excursion so that parents experienced the educational learnings that children gained through such an event.

\section{Background}

The primary school of 205 students serves a concentrated area of social disadvantage in a high-density suburb of south-western Sydney. Ninety per cent of families are from non-English-speaking backgrounds (including Europe, the Middle East, Asia and the Pacific) and speak 16 different languages.

The school has a considerable commitment to supporting these families, providing community language teachers, translating and interpreting services, and an English as a Second Language (ESL) team.

In 2004 it set out to re-form its parents' association, going out of its way to include Asian and Middle Eastern parents by holding weekly parent meetings in Vietnamese and Arabic.

Initially some staff had resisted the project, expressing concern about giving parents "a voice" and empowering them to take on guided leadership roles. It was a priority of the Principal to change this culture.

\section{Engaging parents}

This project was driven by the Principal's conviction that the school had a mission to reach out and involve parents who, because of language and cultural barriers, were not engaged with the school. First she had to overcome doubt and resistance by some staff to the idea of empowering parents. Then it was a matter first of listening closely to what parents said their needs were.

The imaginative responses-English language assistance, parent excursions to interesting places - and the consequent creation of social networks among parents from different cultural backgrounds resulted in parents being provided with something they enjoyed, and could feel themselves benefiting from.

This "enjoyment" factor was important in engaging these parents and helping them overcome their shyness. This was achieved not only by the activities already mentioned but by creating a place where parents could come together to knit, sew or garden. 


\section{Researcher's observations}

The parent excursions had a significant effect. The parents proudly recounted that they were the largest adult group to go to the Powerhouse Museum. They strongly requested that the school organise more of these in the next year. They commented that more mothers had attended the second excursion.

The playgroup, linked with an extensive transition Program, helped both children and mothers to be more confident about starting school, as the children were more familiar with the school itself and comfortable with the other children.

This project used best educational practice in that it started where it could pick up the parents at a point of common understanding and gradually build. The "hands on" approach ran through the workshops, excursions and the play group. The improvement in the confidence of parents, particularly the Arabic mothers, was obvious between the first and second forum. It was delightful to see the bonds of friendship that had developed. It was particularly heartening to see their pride in commenting that they were a true multicultural community.

This project confirms that 'best practice' can only develop from identifying the specific needs of the particular school and parent community. There needs to be consultation and communication in a non-threatening way between all sections of the school community: Principal, parents, teachers, students. This project demonstrated that more than one approach can be successful. There is no single formula. The Principal initially referred to the several arms of the project and these have been a significant feature of this project's success. 


\section{CASE C}

\section{Effective Partnerships in Action: Family Maths for Years 5 and 6}

The school has had a strong commitment to home-school partnerships in mathematics for a number of years with the running of the Family Maths Program in Prep, Year 2 and Year 4. The teachers and School Council agreed that this program, which had been so successful and well supported by the parent community, be extended to Years 5 and 6 .

However, it was agreed that the previous format of the program-one-off 'theme' nights run by the teachers, with some parent involvement in administration and organization-was not adequate as it did not address the key objectives of the project:

For parents:

- become informed about the teaching and learning of mathematics in Years 5 and 6;

- have an opportunity to engage in ' hands on' activities that their children were doing in the classroom;

- gain an insight into how children best learn mathematics, from recent research; and

- be informed as to the transition from Year 6 to Year 7, in relation to mathematics education.

For students:

- have an opportunity to work with their parents in t he types of mathematics activities they undertake at school;

- provide them with assistance in mathematics through knowledgeable and supportive parents; and

- provide them with positive role models as they see adults using and exploring mathematics.

For teachers:

- build on the important links already established between home and school;

- see improved student engagement and confidence in learning mathematics; and

- gain further professional development.

It was decided to revamp the Family Maths Program by conducting four sessions over four nights, three of which would be information nights for parents and the final night would be a family maths night that would involve parents in the presentation of the activities.

\section{Background}

This primary school of 395 students is located in a comfortable middle-class enclave in one of Melbourne's most desirable eastern suburbs. It is an area of high socio-economic families, with minimal numbers of people from non-English-speaking backgrounds, and low proportions of Educational Maintenance Allowance recipients. The school had a small number of international students for the first time in 2005.

Student achievement in all areas of the curriculum is very high, as indicated by the fact that the school consistently performs above like-school and statewide benchmarks in numeracy, literacy and the arts (visual and music). Family expectations for student achievement are high and more than half the students go to independent schools afterYear 6. 
The challenge was to engage parents and families, many from professional backgrounds, who had competing demands on their time.

The Family Maths Program over the past 15 years has attracted $95 \%$ attendance by families but it was felt it needed reviewing and extending for the reasons already mentioned.

\section{Engaging parents}

Knowing that many of its parents were professionals with heavy commitments elsewhere, but also with a strong commitment to their children's education, the school devised a means by which it could make the most of the parents' skills and reward them at the same time by giving them a more direct role in their children's education.

This was the basis for a longstanding program of parent involvement, underpinned by a culture of openness to parents. By skilling up the parents in the way maths is taught these days, coupled with encouraging parents to teach their children in ways they themselves had learnt maths, the school presented parents with an enticing mixture of respect for their own learning and a chance to learn something new, while at the same time fulfilling their desire to give their children the best start in life.

In summary, it was about understanding how to switch their parents on, being open to the idea of parents as teachers, and providing them with the reward of knowing it was all about their children's education.

\section{Researcher's observations}

Quite clearly the new Principal and the deputy Principal were the key motivators and drivers of this project. There is a sense that the application was written with little consultation with the wider school community apart from a brief presentation to School Council and the School Leadership Team.

The Principal was eager to meet with the researcher to develop the program and set a structure in place for canvassing parents to become involved.

The parents were extremely supportive of the project and agreed that the present Family Maths nights, while providing a wonderful opportunity for parents and children to engage in maths activities together, did not inform them as to how maths is taught, or provide them with ways they could assist their children at home. There was a strong commitment to be involved but the timing, late in the year, was a hindrance.

The fact that there was a strong commitment to Family Maths nights already well established in the Junior School with 93-99\% attendance was a strong endorsement. Similarly the concerns expressed by parents that they wanted to know how they could assist their children with maths at home without confusing them by showing them the way the parents were taught at school was a positive endorsement for the project.

Parents play a very active and supportive role in the school and have done so for many years. It is very much part of the culture of the school. This was evident in the discussion with the Principal and deputy and also at the parent forums. There was a relaxed and friendly ambience and parents felt comfortable to openly express their views and concerns.

The school was especially fortunate in having a highly committed deputy Principal who is passionate about parent involvement and parent-run Family Maths nights based on the original model, and an enthusiastic parent community who like to socialise together and support the school in whatever way they can. 


\section{CASE D}

\section{Guiding and Supporting Teens: Taking a Triple Focus, Girls, Boys and Parents}

This project had three prongs that targeted twelve Year 9 girls, nine Year 9 boys and their parents. The students were assessed by their teachers as being at risk of disengaging more from school. They were experiencing social problems or isolation or they demonstrated challenging behaviour problems. While the project built on two existing programs for parents and girls, this was the first time the school had had the opportunity of offering a boys program and a simultaneous parenting program that targeted the parents of selected students.

Girls Going Great-a seven-week program of 2.5 hours each week held during school time and consisting of craft, companionship and learning behaviour strategies to improve connecting and communicating with others. The female chaplain and School Guidance Officer facilitated the program.

Boys Bouncing Back-a seven-week program of two hours each week held during school time where boys participated in school sessions and other active pursuits, eg playing pool, laser force. The program included assisting the boys to develop resilience, improving their communication, setting goals and practising anger management. A Head of Department and a deputy Principal facilitated the program.

Teen Triple P (Ralph \& Sanders, 2002)-a four-week program of two hours per session held once a fortnight for parents of the selected young people. The Positive Parenting Program aimed to manage common developmental issues and teenager behaviour problems such as disobedience, aggression, peer relationship problems, school-based difficulties, family conflict and other everyday difficulties experienced by parents and teenagers. The school chaplain and guidance officer facilitated the program.

\section{Background}

This secondary school in Queensland has 950 students who come from families with a lower-middle to middle socio-economic background. A large number of parents experience financial hardship and find it difficult to meet costs associated with their child's education. About half of the students live in single-parent or blended families.

The school has a reputation for supporting students who have challenging behaviours and as such it often attracts students who have had difficulty in other schools.

Approximately $20 \%$ of students have English as a second language and the school has a reputation for high levels of tolerance and inclusive practices. Young people with physical and intellectual disabilities are integrated into the school, and staff work with families to ensure positive outcomes.

\section{Engaging parents}

Personal contact was the key here. Many of the parents were disaffected by schooling and needed direct personal encouragement from the school staff to become involved. The school also provided programs which supported what parents were trying to do in sometimes very difficult circumstances.

The program resonated with parents: it met their needs in this area. It was not so much a case of finding out what the needs were-this much was fairly obvious - but of persuading parents that the school could help them and was willing to do so. It took 
the work of five dedicated staff to do this. A big lesson from this project is that in some situations the commitment of time has to be almost open-ended.

The celebration at the end of the program seemed to cement the partnership.

\section{Researcher's observations}

The project achieved it goals. There were five dedicated staff who took a keen interest in the program succeeding and they supported the students to the highest degree, always believing they were capable young people who could do well if given the opportunity. Each time I visited the school I felt welcome and each member of staff showed the highest level of support for the project. As a team they had worked out ways of budgeting the funds so that the Year 9 boys and girls and their parents all benefited. This project proved to be a way of connecting disaffected parents who were not regular participants at the school. The celebration breakfast and dinner brought these families together and some connections were made, with parents planning to meet for dinner together at a later date. For some single parents this was particularly welcomed. Making a personal telephone call to parents and inviting them to participate in the parent program was a very good strategy. 


\section{CASE E}

\section{Family and Community Capacity-building}

The project consisted of a mosaic of no fewer than 20 initiatives encompassing Programs on mental health, resilience, stress, learning habits, bullying, cross-cultural tolerance, self-esteem, parenting skills, and academic performance.

The chief elements were called Parent Power Plus, and Forming Friendships. Both of these elements involved parents as partners in decision-making and in implementation.

Parent Power Plus was an initiative of the school's psychologist and grew out of a Program she had devised to engage Year 8 students in their schooling. It consists of a weekly meeting at the school where parents can discuss issues relating to their children and raise any matters they wish about what is happening in the school. It is convened and chaired by a parent, with the Principal, school psychologist and chaplain in attendance.

Forming Friendships consists of breakfasts for members of the various ethnic groups, and a series of excursions to cultural sites such as places of worship.

\section{Background}

This secondary school of 594 students serves one of Perth's most economically and socially deprived areas. It is located in a housing estate with high incidences of single parents, teenage pregnancies, low income, unemployment and welfare dependency. Its student body is drawn from some 50 nationalities. More than one-third of the parents were born overseas, and 27 languages other than English are spoken at home.

The estate has also been the locus of serious cross-cultural violence between two large ethnic groups, the Aboriginal community and the Vietnamese community, stemming from the death of an elderly Vietnamese woman after a raid on her home by a group of Aboriginal youths.

About five years ago this violence spilt over into the school community. At this point, the school began a concerted effort to improve race relations. This led to the creation in the school of the Forming Friendships Program. It is run by a Vietnamese woman who has been engaged by the school to liaise with the Vietnamese community, with help and support from an Aboriginal and Islander Education Officer and the school's parent community generally.

Forming Friendships runs periodic breakfasts at which traditional foods are served, giving those who attend a small taste of the other cultures with whom they share the neighbourhood. It also promotes cross-cultural friendships and seeks to reduce bullying and isolation among students. As part of the current project, there are plans to conduct further cross-cultural activities.

Parent Power Plus has also become an important point of social connection generally for some of the parents, who live in isolated and needy circumstances.

In addition to providing a bridge between parents and the school, it has evolved into a source of educational advancement for parents. For example, some of the parents expressed a wish to renew their own schooling and, with the concurrence of the Parent Power group, the Principal arranged for a visitor from the localTAFE to come and speak to them about how they might do this. 
The Principal, who had been in the school for six years, had a clearly articulated vision for the school and for enhancing the role of parents in it. The essence of this vision was captured in a phrase, "Engaged in Learning", and the first step in this was community capacity-building.

\section{Engaging parents}

The school psychologist was in touch with a number of Year 8 parents over a wide range of issues affecting their children's schooling, and saw how remote they felt from the school system, how marginalised and disempowered they felt generally, and how socially isolated they were.

The school provided a room off to one side of the grounds where parents could meet without having to come through the front office. Initially the psychologist and chaplain helped the parents to come together by personal contact and encouragement, and moderated their initial dscussions about their needs. The Principal listened, answered questions and provided explanations where required.

This was a case where personal contact with parents, listening to their needs, responding in a way that overcame their shyness and disengagements from schooling, and then responding by finding ways to meet their aspirations for resuming their education all played a part.

It then allowed the school to involve the parents in tackling some of the major issues confronting the school community, mainly racial intolerance, but also diet and the fare sold at the tuck shop.

\section{Researcher's observations}

This was a most remarkable school. The Programs and activities covered by the Partnerships project represented only a fraction of the total school effort to build a sense of community, overcome inter-ethnic tensions, support parents and help children break out of the cycle of disadvantage which many of them otherwise might be consigned to, in some cases for life.

The Principal was widely credited with having achieved an extraordinary cultural change during his time at the school, and he allowed his staff and parent body wide discretion to work towards the goal of having parents as well as students "engaged in learning".

The school psychologist was a key figure in reaching out to the parents. She had become a friend and confidante to some of the parents.

The school building where the Parent Power meetings were held had become a focal point for the parent community. This was where issues of genuine concern to parents were discussed. It appeared as if this forum would take over from the P\&C as the main parent forum in the school.

The Parent Power initiative provided a way to bring parents into the school's decisionmaking processes in many other ways, and to provide a means by which parents could themselves resume their schooling through the school's connections with TAFE. 


\section{CASE F}

\section{Retention and Participation Program Engagement and Enrichment Through the Arts and Sport Re-engagement Centre}

These three separate but inter-related Programs make up a comprehensive suite of Programs designed to:

- overcome in younger students a reluctance to attend school;

- remedy anti-social behaviour in a small but disruptive minority of students; and

- keep students constructively engaged at school by providing them with alternative studies tailored to their interests and designed to enhance their employment prospects.

Each Program is in turn made up of a variety of elements. The Retention and Participation Program consists of a Come To School Bus run, a morning nutrition program, a Welcome Room for parents, a student mentor system and a volunteer reading scheme.

The Engagement and Enrichment Program consists of music and sport initiatives, and the creation of a reconciliation garden. The Re-engagement Centre is a kind of schoolwithin-a-school where at-risk students are located in two houses adjacent to the main campus, with intensive lessons in very small groups, monitoring of their conduct by community elders, and employment-related opportunities. It is intended to work with the TAFE to offer practical courses in such fields as mechanical engineering and cattle mustering. Students are selected into the centre on the basis of their risk profile. It is not an easy option for students who simply misbehave.

\section{Background}

This secondary school with an enrolment of 738 students serves an isolated community. It draws students from a broad range of ethnic and cultural backgrounds, most of whom come from blue-collar households. The professional and managerial families in the town tend to send their children away to school.

Forty per cent of students come from Indigenous families, and another ten per cent from Muslim families. There are also significant minorities of students from Middle European backgrounds, and for many students English is a second language.

The cyclical nature of the mining industry, the isolation of the town and the harshness of the climate combine to create a transient population among both students and teachers. This has had a debilitating effect on school morale and on the image of the school. The present Principal has declared that she is committed to the school for a minimum of five years and this in itself appears to have had a positive impact.

The combination of economic disadvantage, ethnic diversity and transience has led to troubling levels of student disengagement and, among a small minority, seriously disruptive behaviour. This in turn discourages even keen students. The three elements of the project are directed specifically at overcoming these negatives and creating positive incentives for all students.

The school has attracted considerable financial and in-kind support from local businesses, and benefits from a substantial investment in local education by a large multi-national mining company. The school's linkages in these areas are strong. 
Between our first and second visits, the school had a major behavioural incident as a result of which 16 students had been suspended. The school convened a meeting of parents and about 50 turned up to discuss the issues. What the staff feared would turn into an unpleasant confrontation in fact turned out to be a most constructive discussion, leading to the holding of a barbeque which many of the suspended students attended. Their behaviour seemed to improve thereafter.

\section{Engaging parents}

Many ways were used to reach out to the parents: a breakfast Program; taking teachers out to Indigenous communities to show parents what their children had done in school (rather than the conventional parent-teacher meetings in the school); using personal contact to bring parents in to forums to discuss specific ideas such as the Reengagement Centre, and when a crisis arose responding openly by inviting aggrieved parents in to talk about the suspension of their children.

The school also employed a number of Aboriginal and Islander Education Officers whose main responsibilities included staying in touch with Indigenous parents.

Again personal contact, an open culture from the Principal down, an obvious willingness to be sensitive to parents' needs, and a preparedness to put an effort into finding creative solutions for students at risk all contributed to the engagement of parents in this very demanding setting.

\section{Researcher's observations}

As with so many of the disadvantaged schools observed in this study, this secondary school appears to have benefitted from a Principal who is passionately and energetically committed to giving students the best possible chance to break out of the cycle of economic and social deprivation.

Her appointment nearly two years previously had led to changes of personnel among the school leadership, most of whom are now women, and they appear to form a cohesive and determined team. As it happens, it is women who also provide most of the leadership among the parent body and in the Indigenous community. This somewhat matriarchal network has a readily shared understanding of the causes and consequences of the issues, and of what is needed to tackle them.

The school is also closely networked into the other relevant services-police, juvenile justice, state welfare, the TAFE, and health providers.

A police officer is attached to the school as part of a pilot project by the WA Police Service to assist with early intervention among young people. A youngish and friendly man, he has none of the authoritarian bearing stereotypically associated with police and has an easy relationship with the Principal.

The meeting to discuss the implementation of the Re-engagement Program was chaired by an Aboriginal and Islander Education Officer and attended by various agencies and six parents, one of whom was the father of a couple of tearaways who freely admitted his boys were a problem, and explained their troubled family background. The parents had significant input into the discussions.

There has been very significant progress towards the establishment of the Reengagement Centre, the breakfast Program is well under way and the other elements of this multi-faceted project all seem to have moved along. 


\section{CASE G}

\section{Welcome New Arrivals}

This project was focused primarily on strategies to engage families with the school, and in particular to find innovative ways to support "new arrivals".

The project group was primarily focused on active strategies to make the transition to school for new parents/families as smooth as possible.

A number of activities were implemented over the two to three months of the research, including:

- appointment of project co-ordinator;

- establishment of a two-tier buddy scheme;

- teacher/staff skill register;

- commencement of multilingual website;

- "Cook/Talk/Share" Programs where different cultural groups hosted culinary events for families; and

- parent morning coffee meetings (run just prior to school assembly, so families could combine the two events).

\section{Background}

This primary school is a multi-campus 500 -student primary school in the suburbs of Adelaide, with a significant multicultural population. Its catchment includes substantial areas classified as low socio-economically, although there are some high socioeconomic areas. About one-fifth of students receive government support.

The school is located on the fringes of Adelaide and attracts students from the surrounding rural area as well as the suburbs.

It is one of the most ethnically diverse schools in South Australia with $45 \%$ of its students coming from non-English-speaking backgrounds. More than 50 nationalities are represented in the student body, including $1 \%$ Indigenous.

Few of the NESB families had traditionally become involved in school activities and the main focus of this project was to engage them more effectively.

\section{Engaging parents}

This was an example of how a school was able to use its own position in the community to create social networks among parents. +lts Buddy system connected families who would otherwise probably not have become connected, overcoming barriers of culture and language, and creating a welcoming atmosphere for new arrivals.

Personal contact with parents by the project co-ordinator-a parent appointed by parents-was critical, as was the preparedness by the school to empower the parent body in this way.

Also the "Cook/Talk/Share" activities were not overtly educational, nor did they require any particular expertise. However, they provided an enjoyable social occasion, so once again the "enjoyment" factor was important. 


\section{Researcher's observations}

The project appears to be truly driven by parents for the school community. The results to date are promising, and the feedback thus far suggests that the partnership project initiatives are sustainable, with a high level of parent involvement.

This school has unique language and communication issues - with a significant number of families from non-English speaking backgrounds. Over 100 families are Chinese arrivals, and more than 30 each of Korean and African origin.

The project has enabled this rich multicultural environment to create effective linkages that appear to be relevant and stimulating higher levels of participation. 


\section{CASE H}

\section{Personality, Resilience and Learning Styles - Understanding Our Children and Ourselves}

The school held a conference for parents in this regional Victorian town and surrounding areas around the topic of "Personality, Resilience and Learning Stylesunderstanding our children and ourselves". The conference consisted of two sessions, each lasting for four hours and held at a comfortable venue in the town, with lunch provided.

The guest speaker was Dr Loretta Giorcelli, who is a consultant in the fields of child development, special education and learning and behaviour in children and adolescents. She covered a variety of topics relating to stages of child development, parenting issues, understanding children's temperament and learning styles, building emotional resilience in children, learning and behaviour, and social skills in children. The material also looked at family-school relationships and ways parents can support their children in their learning and school life.

A shorter bridging session was held between the two main presentations for several interested parents, by the parent group's president who was the project co-ordinator. This session provided an opportunity to discuss issues and ideas gained from the first session and practical applications for these in family and school life.

The major initiators of the project were the Principal of the school and the project coordinator. They worked closely with parents, teachers and children in the development of a family-school partnership that focused on:

- coping with different personalities within the same family;

- buoyancy and resilience;

- developing advocacy and leadership skills (as parents and in the children);

- meeting children's emotional needs whilst dealing with stress in one's own personal relationships;

- sibling rivalry, competition and quarrelling;

- self-esteem for the children and for parents;

- peer pressure and the ways that children can deal with it;

- breaking recurring patterns of poor child and parent reactions to given situations;

- father-child relationships; and

- step-parenting and the issues that may come from this in regard to discipline at home and in school behaviour.

\section{Background}

This is a primary school of 300 students in the Victorian goldfields, a rural area which is also an important tourist destination. It serves a monocultural community of low to medium socio-economic status, and the challenge was to broaden the community's valuing of difference.

The school was involved in the National Safe Schools Project, which focused on community connectedness and on strengthening relationships at school. Two principles issues emerged from its work in that project:

- parent education; and

- learning styles.

The school saw the present project as a way of extending and developing work that had already begun in these areas. 


\section{Engaging parents}

The appointment of a vibrant and energetic parent was of great importance in making the project happen. Personal contact with parents by this person and a core team of parent helpers was also most important.

This really did seem to be a joint enterprise of the Principal and the parent co-ordinator where decision-making was genuinely shared.

The activities were tailored to what parents had said would interest them, so again listening to parents' needs was important, as was the provision of an enjoyable venue, a good meal and an interesting speaker.

\section{Researcher's observations}

The major driver for this project was the president of the parent club who worked closely with the Principal and with a core group of four or five parents. The project co-ordinator is a social worker and was able to bring some of those skills into her work with the parents, and in organising a number of activities that involve parents and the school.

The Principal fully supported the initiatives of the core group of parents. She also noted that the other staff members were fully supportive of the project. The forum where the guest speaker addressed the parents seemed an outstanding success. The issues addressed were those that the project co-ordinator and the Principal had spoken of earlier as being of concern in their particular school and community. Of particular interest was the way that these two women worked with a group of 10 or 12 parents for between-forum activities. This follows a successful professional development practice of trialling strategies in the home and classroom, and then reporting back to the next session for discussion, evaluation and further development.

The school seems to have met all the objectives it set for itself in this project and is now looking for ways to take them further. The conferences/forums were an excellent idea, and they were very well supported by parents not just from the town but some of the surrounding areas and schools. Each conference attracted 50-plus people. The conferences/forums were very professional, with the venue being attractive and the catering excellent. Many books were ordered, at the speaker's suggestion, for the parent library.

A major reason for the number of parents attending and remaining involved was the one-to-one invitation and talking to individuals that the project co-ordinator, in particular, and the core group of four parents undertook: personal invitations to parents; encouraging them to attend; and highlighting particular aspects of the forum/ conference that the parent might find interesting. It was very time-consuming but it was also effective. They are trying to gradually extend relationships by using the core group of parents to work in the wider school community. 


\section{CASE I}

\section{Extending School and Family Partnerships Through School- Based Projects}

The project initiatives were essentially a continuation of existing projects.

-The Fountain Project- A local artist has designed a water sculpture that represents the school values and beliefs, and the parents and children are working together to complete the mosaic tiling around the fountain.

- Parent forum - Representatives from each year level encourage communication and school involvement among parents within that classroom. The parent representatives meet on a regular basis to achieve common goals for the school.

- Minor initiatives - Recruitment and maintenance of Support-A-Reader Volunteers, permaculture garden, healthy eating plan for the school canteen menu.

\section{Background}

This primary school in regional Queensland has 411 students, and is situated in a semi-rural community with a population of approximately 1500 people. It is a lowmedium socio-economic area where approximately half of the students come from single-parent families. The school values and encourages parental involvement and believes the co-operation produces positive outcomes for their students.

The Principal has recently retired. When he first came to the school he inherited a school that was somewhat fractured and separate from its community. He spent much of his energy developing strong school-community relationships. A parent was employed as a community enhancement officer to improve communication between parents and the school.

The importance of this has been increased by the pressures of a large new housing development, which is turning this semi-rural village into a town. In the face of this social transformation, the school is anxious to bed down strong community ties to help preserve the unity that has been developed in recent years.

The school's community enhancement officer plays a vital role in strengthening parent-school relationships. She is instrumental in providing opportunities for interaction between parents, school and the wider community.

A number of school-community projects have already been completed as a result of the school's vision of "learning and growing together".

The acting Principal has been at the school for a number of years and has continued to foster the positive parent-school relationships.

\section{Engaging parents}

The appointment of a community enhancement officer was of critical importance here. The school was alive to concerns in the community about the consequences of the incipient housing development, which was going to transform their village, and was prepared to be the venue of community capacity-building, using a range of initiatives aimed at attacting the involvement of many people with different talents and interests.

It was similar in some ways to another school where a mural had been built. Fathers became engaged when they were able to see it as a "building" project, not an "arts" project. Here, people became involved because they were approched personally, the 
school showed it understood their needs, and the various elements of the project provided activities than a wide range of people could enjoy.

\section{Researcher's observations}

This school has a vision of school-community partnerships. They have already set things in motion by employing a school community enhancement officer to foster strong communicative links and active community participation. This, together with the formation of a parent forum (in addition to the $\mathrm{P} \& \mathrm{C}$ ), gives parents and community members a voice and has empowered the school community.

It is a very welcoming school community. Much is already in place to facilitate strong parent-school relationships. A number of projects are already under way, including the fountain project, which was to be completed by the end of 2005.

There is a room available for parents and visitors. The school has limited space so it is shared with the music teacher. The sign outside the door says, "Parents' and visitors' meeting room. Please feel welcome to use this room for Information Exchange, Discussions, Learning Workshops, Lunch breaks and Social Activities". Tea and coffee are readily available. This is suggestive of the extent to which the school is willing to go to foster happy and positive parent relationships, and to encourage the parents to stay at the school and interact with each other.

The School Community Enhancement Officer plays a vital role in forging a strong bond between school and community. She seeks out opportunities that may add to the learning and participation of parents and the wider community in school initiatives.

The focus is on trying to capture the interest and the active participation of parents who are not readily available or are not as active in school initiatives as the current group. All these factors, in addition to the enthusiasm and forward thinking of the Principal, suggest that the school could be an exemplar for schools wishing to a engage in successful and effective family-school partnerships. 


\section{CASE J}

\section{Raise-raising Achievement in Schools (E)}

The project consists of training volunteer parents in basic classroom skills and in special literacy and numeracy Programs, then rostering them into classrooms where they work alongside teachers in block teaching of these core subjects.

\section{Background}

This Catholic primary school of 408 students in an old inner suburb of Perth serves an area that is being rejuvenated by a steady influx of young professional and middleclass families. The school has a highly stable population, $80 \%$ of which are considered to identify themselves clearly as Catholic. Only about $7 \%$ of households qualify for a health card.

The school is growing steadily as it progressively introduces a second stream of students. This will take the enrolments from 400 to about 600 .

Over at least the past decade, the school has developed a culture in which parents have been actively encouraged to participate in the delivery of education in partnership with the teachers. There was a positive intention to try to bring parents into the classroom as part of this.

About four years previously, a teacher of a Year 1 class was approached by a number of parents wanting to assist in the classroom. She ran a workshop for as many of her parents as wanted to come, and from those who attended she drew volunteers to assist her as required. This is essentially the model that is now being expanded across the school in the specific curriculum areas of literacy and numeracy. The formerYear 1 teacher is now an Assistant Principal.

At the request of the teaching staff, the P\&F resolved to provide additional resources in the specific areas of literacy and numeracy. When the new resources had been purchased, the teaching staff gave demonstrations to the P\&F to show them what had been bought and how it would be used.

The school now wanted to take this one step further and provide workshops to show parents how to use these resources at home. The objective was to have consistency between the teaching techniques used at home and those used at the school in literacy and numeracy.

The present Principal inherited this culture of parent partnerships and, according to the teaching staff and to the parent leadership group, has been responsible for both placing sensible boundaries around it and deepening it. His message to parents is, "This is your school".

\section{Engaging parents}

This school has been engaging its parents for a decade or more. The culture of openness to parents is well-established. The parents had been specifically invited by the two key teachers in this project to come and talk about curriculum materials for use in the classroom.

This well-educated parent community, accustomed to being part of the decisionmaking in the school, responded enthusiastically and were then asked if they would like to learn to use the materials themselves with a view to helping out in the 
classroom. There was great appeal in this because it gave them a concrete way of helping their children learn.

\section{Researcher's observations}

This school had a "feel" about it; as soon as you walked into the place you had a sense that it was an unusually positive environment. The Principal came straight out of his office as soon as he heard my voice at the reception desk, shook my hand, took me in directly to his office and began to talk rapidly and enthusiastically about the school, the Program and the day he had mapped out for me. This included a staff morning tea at which there were birthday cakes and singing for staff whose birthday fell on or about the day.

The assistant Principals, who had carriage of the project, spoke with great warmth of the Principal's leadership and his willingness to build on the work of an admired predecessor, as well as of his openness and humaneness in his dealings with students, staff and parents. These were themes I heard repeatedly, from staff, parent representatives and the parents who came to a forum in the evening.

The existence and promotion of clear and common values was a feature. The values espoused by the school were framed in a visually bold document hanging in the foyer directly opposite the front door. Values were referred to frequently, as was the importance of consistency between the values of the home and of the school. 


\section{CASE K}

\section{The Parent Reference Group}

The project consisted of establishing and maintaining a parent group within the school community that is not bound by traditional structures or traditional relationships between the school and parents. Its functions are to promote multiculturalism in the community, increase participation by parents in the life of the school, improve communication between the school and families, and reduce social differences.

The group holds regular informal Wednesday morning meetings, which parents are encouraged to attend and meet with a community liaison worker. The group also organises multicultural morning teas where a range of ethnic foods are sampled and people from different ethnic groups in the community are brought together.

A parent centre in the new library is being set up, providing books, magazines and electronic materials on parenting and primary education.

An advertising campaign, using posters and a column in the school newsletter, has begun to inform the community of the existence and function of the parent group.

\section{Background}

The school is situated in a suburb of lower socio-economic standing in outer western Sydney. There is a diverse range of languages and cultures in the local community. Sixty per cent of the children are from an NESB background and the figure for Kindergarten in 2006 was expected to rise to $70 \%$, reflecting increased migration into the area. A community liaison worker has been employed five hours a week for a number of years, undertaking pastoral work and occasional home visits.

The new school leadership proposed a project involving a body that would reach out to parents and help them in their integration into the local culture and school community and welcome their participation in school life.

A feeling was expressed that, while the school had traditional parent structures such as a mothers' club and a fathers' club, anxieties and tensions had diminished their effectiveness. Power had been exercised in these bodies by a limited few over a number of generations. It was felt these parent groups merely served the school's interests as fundraising bodies and that a new group was needed that could operate outside traditional structures and whose ownership would lie in the hands of many parents. In addition, traditional parent body structures in the school had not embraced the multicultural aspects of the school community. A new parent group networking with the community liaison worker would act as a voice for parents in passing on information to the school community.

\section{Engaging parents}

It was the pastoral role of the community liaison worker which was seen as a bridge into the partnerships. The person had been employed in this role for 20 years, and had established good links with the various groups in the parent body. This demonstrates the need to invest time in initiatives like this. Newsletters, advertisements and other such devices were used as back-up but not as the primary vehicles of communication. The parents had also become engaged because the new group had none of the old power structures and was invited to play a role far wider than the conventional one of fund-raising. 


\section{Researcher's observations}

I feel there is an enormous tension between the school and the parents' needs and rights.

This statement by the community liaison worker indicates one of the motivations driving a sea change currently underway in the school. There has been an acknowledgment that in the past the school has not addressed its multicultural aspect with its projects. The actions of the school executive and the community liaison worker combined with new elections for parent clubs have provided the opportunity to establish a new parent body more in keeping with the multicultural nature of the school.

The school is seeking to overcome past failures and limitations in school-community relationships and to put aside a "them and us" mentality. It wishes to be seen in future as a truly multicultural school where the community is genuinely and fully involved.

The process of establishing a new parent body is necessarily a careful and patient one and the group is working steadily on a number of fronts. It needs to be carefully nurtured, otherwise it will collapse easily. The project is being guided successfully through its early phases by confident, energetic and committed staff with much hope for the future. 


\section{CASE L}

\section{Connecting with Our New Arrivals}

The project plan involved:

- finding effective ways to consult with and engage the new migrant groupsprimarily Africans of Sudanese origin;

- increasing the level of involvement of the local Migrant Resource Centre in the work of the school;

- employing and training a Sudanese family member as an aide to assist in the project deliverables; and

- running some relevant activities to test effective engagement actions for the Sudanese families.

\section{Background}

This is a 200-student Catholic primary school in Tasmania serving a generally lower socio-economic demographic. Traditionally it has not had a high level of involvement by parents and families. Like a number of the other schools in Tasmania, it has had a recent influx of migrants of African background, mainly Sudanese. This has presented an enormous challenge for the school. However, by contrast with the existing population, many members of the Sudanese community are tertiary educated and come from professional backgrounds in Africa.

At the start of this project, the school had made some progress on its project. However, for such a tiny school, it was an ambitious undertaking and the Principal was finding resourcing the project a "stretch". The grant money enabled the school to employ and train a Sudanese parent in a liaison role.

By the end of the research period, a number of milestones had been completed. A Sudanese parent had been appointed to the project role and was undergoing support and training at the local Migrant Resource Centre.

By the end of the research period, this parent had already run some in-school activities. Some had focused on information exchange and others were craft or food-based. She had also co-ordinated the first parent-teacher interviews for some of the Sudanese families, which have already led to changes in strategy for some students and their families.

The project is very focused on improving the learning outcomes for the students, and anecdotally this is already providing some positive outcomes.

A total of six 'gatherings' had been run or were planned before the end of 2005, and the school's ESL co-ordinator was attending so she could make positive connections with the families.

\section{Engaging parents}

First, this school made a leap of imagination that many individuals and institutions find difficult; it put itself in the shoes of the newly arrived migrants and reflected on what they might need. The school then looked around for ways of meeting those needs. Its own limited resources forced it to look outside. It identified English-language tuition as critical and set about finding ways to meet that need. It also appreciated the qualities within the Sudanese community, and the appointment of a Sudanese woman to co-ordinate the project not only reflected this level of appreciation but created an 
immediate bridge into the community. Once again the appointment of a parent in a liaison role has proved pivotal.

\section{Researcher's observations}

Due to the nature of the project, and difficulties getting the families into the school (as well as the obvious language issues), I have not been able to meet with any of the Sudanese families. In hindsight, this was an ambitious project, which has nonetheless so far has had a very profound and positive impact. Despite the modest project objectives, the learnings so far appear to be significant.

It would seem that the Principal has little support in a resource sense-although the project is obviously well supported in a conceptual way by his team.

The appointment of one of the Sudanese parents as an aide and coordinator is significant and the Principal was adamant that this would continue into 2006.

In terms of the Draft framework, this project is all about stimulating basic communication to fundamentally improve learning outcomes. Given the history of the school, and the previous lack of connections with the new migrant group, the project has been successful-albeit in a modest way.

Outcomes have been very concrete and basic-but important. The Principal commented that the "provision of correct uniforms and a tailored payment schedule" and "having the first effective parent-teacher interviews (in some cases, the first time the Sudanese parents had met their child's teacher)" were in themselves significant outcomes. 
